\title{
Structuring Knowledge of Life-Cycle Consequences for Supporting Concurrent Design Exploration
}

\author{
J. Borg \\ Department of Manufacturing Engineering \\ University of Malta, Msida MSD06, Malta \\ Tel: (+356) 32902366, Fax: (+356) 343577 \\ email:jjborg@eng.um.edu.mt
}

K.J.MacCallum

CAD Centre

Department of Design, Manufacture and Engineering Management University of Strathclyde, 75 Montrose Street, Glasgow G1 IXJ, UK Tel: (+44) 141-552-4400 ext.3134, Fax: (+44) 141-552-3148

email:ken@cad.strath.ac.uk

\begin{abstract}
This paper is concerned with the development of a model for knowledge of consequences which can support provident reasoning design. The work is focused on part design synthesis decision making so as to support individual designers engaged in life-cycle design exploration. The emerging model is one based on structured relationships between a number of aspects which are considered to be the source of life-cycle consequences, namely Features $[\mathrm{F}]$, Parameter values [V], Material [M], Constraints [C] and Process [P] factors. The approach is seen to be a framework for the systematization of domain knowledge which can subsequently be employed in a Knowledge Intensive CAD system for supporting concurrent design of components. Examples in the approach are drawn from the domain of injection moulded plastic components.
\end{abstract}

\section{Keywords}

Concurrent Engineering, Life-Cycle Consequences, Design Exploration, Providence. 


\section{INTRODUCTION}

High costs and delays due to problems arising in manufacturing and other life-cycle phases from decisions (Andreasen et al. 1990) committed during the design phase is the motivation behind the ongoing research programme being reported in this paper. The view taken is that these problems are evidence of the difficulty which designers have in taking into consideration the life-cycle consequences resulting from their design decisions. There are a number of manual and computer based tools which are employed to support particular aspects of lifecycle design such as Design For Manufacture (Corbet et al. 1991). These approaches however take a narrow view by considering one life-cycle phase at a time, therefore ignoring any interactions between the different phases and a late view by being applied after a part has been designed and not whilst committing the design decisions. This is in contrast with our view of concurrent engineering, based on a definition by (Olesen 1992) who states that concurrency requires simultaneity, integration and providence. The approach in this paper concentrates on providence, defined as:

"Providence means to foresee and take into account aspects, which are fixated or determined at the design stage"

This view of concurrent engineering based on providence highlights the need to take into consideration the life-cycle consequences and their interactions during the design phase itself. Examples from the domain of thermoplastic products presented in this paper reveal that the organization and provision of appropriate knowledge can support this life-cycle design exploration during design decision-making. Structuring knowledge of life-cycle consequences is seen as an essential part of a Knowledge Intensive CAD (KICAD) system which supports providence in concurrent engineering. The research objective is therefore one of generating a knowledge of consequences model which enables provident reasoning to take place during design decision making, so as to infer problem-specific life-cycle consequences and their interactions.

To develop an understanding of providence, the following concepts are used in this paper:

- synthesis decisions: definition of aspects (add, specify etc.) to the evolving part model, in terms of geometric form and physical definitions (e.g. type of material, surface finish etc.);

- explicit decision: a decision concerning a part feature, attribute or value consciously made by the designer; e.g. hole orientation angle $=45^{\circ}$;

- implicit decision: a decision concerning a part or a life-cycle attribute implied by an explicit decision; e.g. use split cavity type mould (because hole orientation angle was explicitly defined as $45^{\circ}$ );

- life-cycle phase: a phase through which a component goes during its whole life, namely: design, manufacture, assembly, use, service and disposal. Different parts may require different processes within life-cycle phases, such as for instance in manufacturing due to different materials, surface finish etc.;

- life-cycle consequences: resulting effects due to committed synthesis decisions, these being: 
- creation of a new decision space in the same or different life-cycle phases;

- life-cycle behaviour;

- introduction of new life-cycle constraints because of new decision spaces.

- performance measures: these are a number of measurable quantities of part performance when placed in an environment in a particular life-cycle phase, that are involved in all functional areas. They include: design requirement specifications, costs, throughput time, quality, efficiency, flexibility, risk and environment.

- life-cycle behaviour: the behaviour of the part in different life-cycle phases as reflected by values of performance measures.

- constraints: limitations to the independent parameters of a design solution e.g. length $<200 \mathrm{~mm}$.

- independent design parameter: a parameter which can be directly defined by the designer e.g. the length of a rectangular plate; on the contrary, dependent parameters such as mass are derived from the independent parameters length, breadth, thickness and density.

- knowledge model: relationships between the design space and the life-cycle behaviour space embody what is being termed knowledge of consequences. The description of these relationships should provide structure to this knowledge. The knowledge model is therefore concerned with what factors should form part of the structure, and with how these factors should be organized and related to each other and not with the representation formalism.

\section{DESIGN PROBLEM BACKGROUND}

\subsection{Dispositional Mechanism}

There are many cases which demonstrate that decisions made during the design phase have an effect on different life-cycle phases in terms of performance measures such as cost, time, quality etc. As an example, a designer's decision (Figure 1) to define a thermoplastic plate with a sharp corner (i.e. radius $=0 \mathrm{~mm}$ ) will influence the type of fabrication methods (in this case, spark erosion or cavity construction) that can be eventually used to generate the respective mould cavity. This results in an influence on the performance measures cost and time of mould construction. A different decision (e.g. radius $=5 \mathrm{~mm}$ ) would result in different fabrication methods, such as cavity milling and would have a different effect on cost and time. This phenomena termed a dispositional mechanism (Andreasen and Olesen 1990) has been employed by (Olesen 1992) to demonstrate that the theory of dispositions can be used by 'the designer to foresee and choose the parameters of the product which optimize the conditions during production and product life.' 


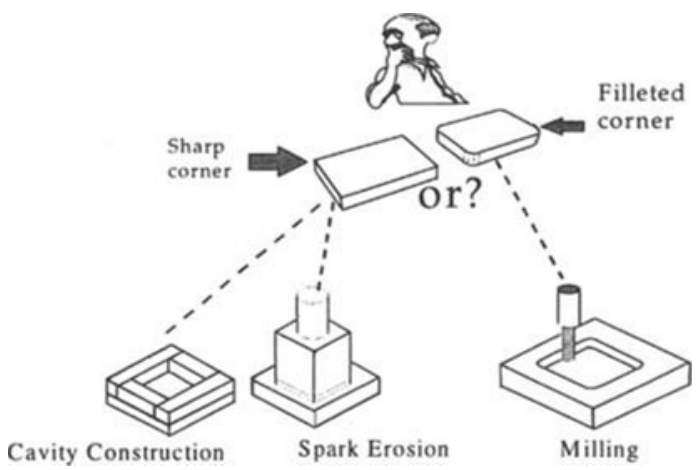

Figure 1 Typical Decision Consequences.

\subsection{Propagation Effects}

The analysis of a number of thermoplastic part design decision making case-studies resulted in evidence that the concept of dispositions can be extended, as the resulting effects of design decisions can themselves propagate further onto a number of life-cycle phases, a phenomena being termed propagation effect i.e.

An explicit decision made to achieve an intended effect gives rise to other decisions and influences on performance measures in other life-cycle phases. The cumulative consequence resulting from the explicit design decision is termed the decision's propagation effect.

For instance, a designer may consciously i.e. explicitly make a decision known to have a positive disposition when designing two plastic parts (for some reason each made from a different material) in a way which allows them to be ultra-sonically bonded, this schematically illustrated in Figure(2). This explicit decision results in a permanent bond and keeps the number of parts to a minimum, thereby abiding with a Design For Assembly (DFA) (Corbet, Dooner et al. 1991) rule. It also keeps the mould design simple and therefore cheap, compared to a snap fit which would introduce mould design and construction complexity and hence higher cost. However, what is not evident from this disposition is that if the sub-assembly is to satisfy for instance recyclability concerns, then the disposition resulting from the explicit decision made by the designer propagates negatively onto the disposal phase's performance measures, because it is difficult, time-consuming and expensive to separate permanently bonded parts. 


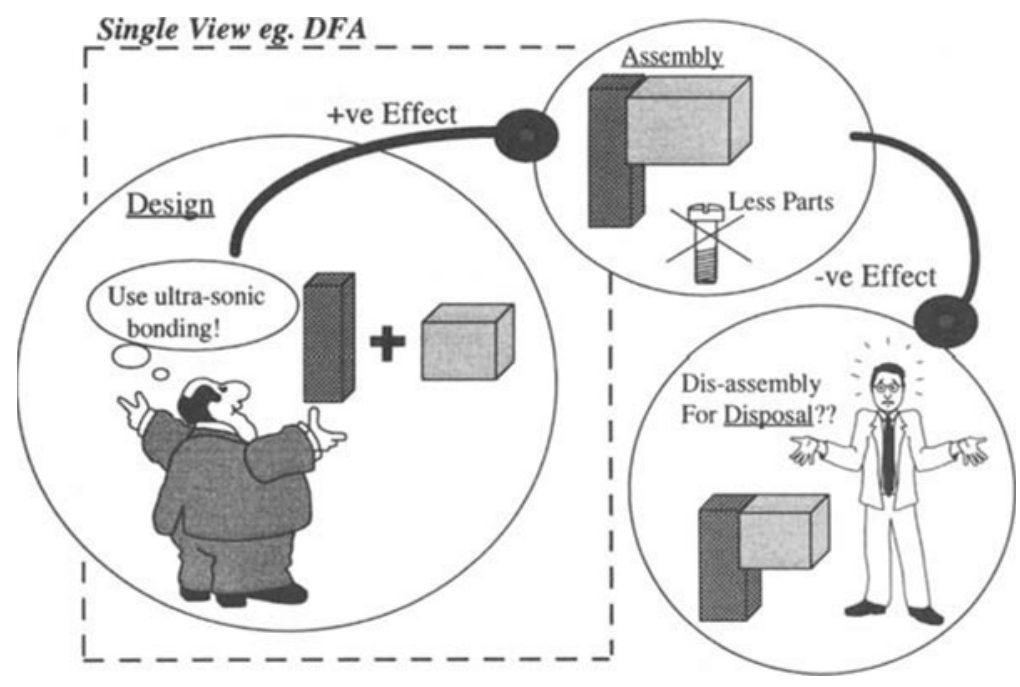

Figure 2 Propagation Effects.

This example highlights that it is therefore not enough to reveal and control the designer's dispositions - rather there is a need to have a wider insight into the interactions between the different life-cycle phases resulting from such propagation effects. This problem is the result of design methods/tools taking a single, narrow view towards the evolving design solution.

Thus, designers can be said to be frequently unaware of the life-cycle consequences which their explicit decisions propagate, this giving rise to a difficulty in generating design solutions satisfying simultaneously the different life-cycle phases. The hypothesis put forward in this research programme is that decision-making under such ignorance can be reduced if knowledge of life-cycle consequences is made available to support providence during early design. The emerging problems to such providence-based design decision making are therefore the systematization (Tomiyama et al. 1995) of the appropriate knowledge and then its representation in a KICAD system. In summary, the problems identified with respect to this research programme are :

- the traditional design decision making process takes a narrow focus;

- designers are relatively ignorant of the life-cycle consequences [LCC] they generate;

- a structure of knowledge is required to support providence which includes simultaneous recognition of different life-cycle consequences. 
Table 1 Limitations To Design Providence

\begin{tabular}{ll}
\hline & Limitations \\
\hline Design Team & -teams have difficulties in recognizing the complex dispositional effects of \\
& decisions (Andreasen and Olesen 1990); \\
& -does not ensure that knowledge about making design decisions and \\
& compromises will be available (Finger et al. 1989); \\
& - decisions with potential life-cycle consequences can be committed in the \\
& interim period between meetings; \\
& -teams present many logistic, scheduling and other management difficulties \\
& (Bowen 1995) making providence difficult to achieve; \\
Virtual Teams & -As above except that team members' physical location is not a problem; \\
& -Time zones between different team members' locations may be a problem. \\
DFX & - Single view i.e. Interactions/propagation effects not handled \\
& - Feedback is generic (Molloy et al. 1993) and not problem-specific; \\
Expert & - employed for design analysis and not for exploration \\
Systems & - knowledge is not organized in terms of resources which have to be \\
& coordinated (MacCallum 1991); \\
& - limited in handling interactions/relationships (MacCallum 1991); \\
Constraint & - narrow domain and hence narrow focus; \\
Networks & - require a predefined network of parameter relationships (Bowen 1995); \\
& - design problem has to be expressed as constraints; \\
FMEA & - design modelling not readily associated with decision making process; \\
& - failure modes are identified late (Norell 1993) the design process; \\
& - Providence depends on the user's design solution interpretation; \\
& - single focus at a time i.e. does not handle propagation effects;
\end{tabular}

\subsection{Current Approaches To Design Providence}

There are a number of approaches that designers use to preview and control life-cycle consequences. One approach is through the use of cross-functional design teams (Askin et al. 1994) to bring all expertise together, and more recently through virtual tiger teams (Cleetus 1993), which allows geographically separated team members to work together. Although design teams and virtual design teams offer a number of advantages to design, they still present serious limitations to achieving early design providence, as highlighted in Table 1. Tools of the "Design For X" type, essentially offer a checklist (Corbet, Dooner et al. 1991) of do and don't guidelines to ensure that a design satisfies the ' $\mathrm{X}$ ' area. The major limitation with respect to providence is that these stand-alone DFX tools are employed as analysis tools when as (Gardner et al. 1993) state, major design decisions have already been committed. Another approach which can be claimed to support providence is the use of design expert systems (Borg et al. 1995). Although expert systems have a predictive modelling power, their limitation to design providence is mainly due to the way the knowledge is organized, making it difficult to explore trade-offs between life-cycle aspects of an evolving design solution. Constraint networks are another type of tool which have been used to assist designers in 
avoiding the generation of life-cycle problems by supporting cooperation between multiple perspectives (Bowen 1995). A limitation of the constraint networks approach is that they concentrate on solving a problem expressed as constraints, but do not readily support design modelling with its associated decision making process. Another common tool employed to avoid potential design solution problems is Failure Modes and Effects Analysis (FMEA) (Healey 1994). This and other analysis related tools are essentially employed late in design, after major design decisions have already been committed. The limitations of the above mentioned approaches are summarized in Table 1.

\section{KNOWLEDGE STRUCTURING}

The approach adopted to modelling knowledge of life-cycle consequences is through the structuring of relationships between design decisions and life-cycle behaviour. In this section, the structuring framework is presented in a semi-formal way, with relationships for design synthesis decisions concerning the addition and definition of features (Wierda 1991) to a part. Initially, the work has been focused on components as these are made from a single material. Consequently, the examples presented in the following sections will refer to a case study in which a hole feature is being added to a plate feature for some desired intent.

The notation used in the following sections is:

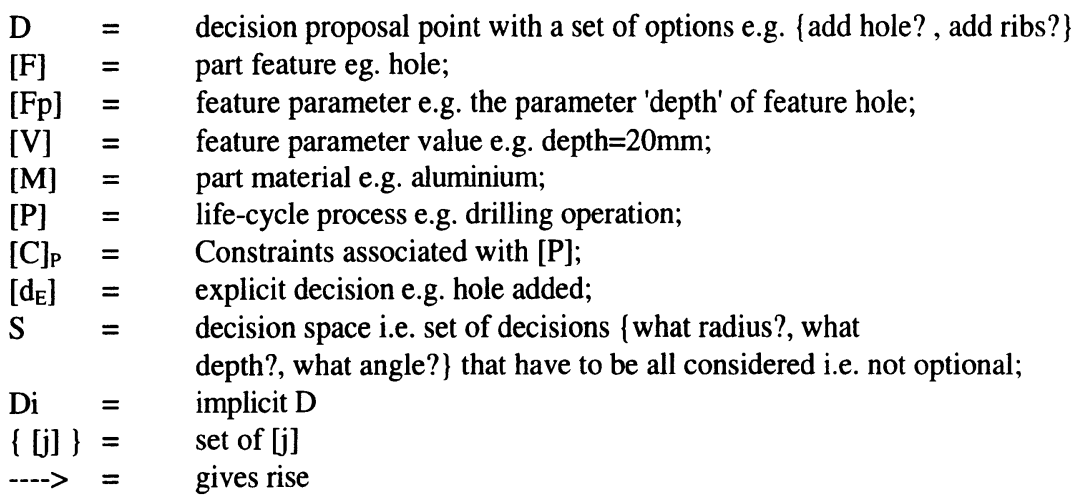

\subsection{Sources of Consequences}

As a result of the identified problems, it is considered necessary to provide designers with problem-specific providence, rather than providing designers with generic providence, such as in the case with for instance traditional DFX tools. The work has so far identified a number of factors, which when structurally related give rise to problem-specific life-cycle consequences as will be described in the sections following.

Feature [F] Factor 
The addition of a feature to a part introduces a set of feature parameters which require values. Each type of feature has its own parameters. For instance, adding a hole to a part will give a decision space of \{radius?, depth?, angle?\}, while the addition of a different feature such as a rib will create a decision space \{rib height?, rib width? draft angle?\}. This means that the explicit decision made concerning feature selection is a source of a decision space $S$. This relationship can be described as:

$[d]_{E}\{[F]\}--------->S\left\{[F]_{P}\right\}$

read as:

An explicit decision $[d]_{E}$ concerning the selection of a physical definition such as a feature $[F]$, gives rise to a decision space 'S' related to feature parameters $[F]_{P}$.
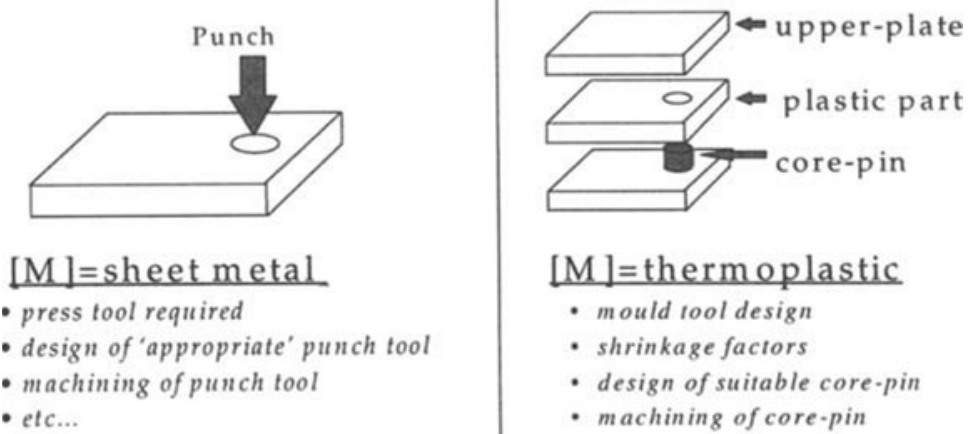

\section{$[\mathrm{M}]=$ therm oplastic}

- mould tool design

- shrinkage factors

- design of suitable core-pin

- machining of core-pin

- formation of weld-line

- Scrap due to welds etc...

Figure 3 Influence of material [M] factor.

\section{Material [M] Factor}

On its own, the relationship in (1) is generic and is therefore not sufficient to generate problem-specific providence. For instance, the decision add hole can be applied to different parts made from a different raw material. Therefore, depending on the material specified (e.g. ABS thermoplastic vs sheet metal), the life-cycle consequences will be different (see Figure 3), due to the possible processes that can be employed, this relationship being:

$[d]_{E}\{[F]\}+[d]_{E}\{[M]\}-------->D_{1}\{[P]\}+S\left\{[F]_{P}\right\}$

read as: 
An explicitly committed decision concerning a physical definition such as a feature i.e. $[d]_{E}\{[F]\}$, together with the explicitly committed decision specifying the part material $[d]_{E}\{[M]\}$, give rise to a decision point $D_{I}\{[P]\}$ concerning possible lifecycle processes options together with the feature parameter decision space $S\left\{[F]_{P}\right\}$.

It should be noted that the decision point $D_{1}$ concerning possible life-cycle processes is implicit to the designer and as a matter of fact has traditionally been left to the process planner to reveal the relevant set of possible life-cycle processes and select a suitable process.

\section{Process [P] Factor}

$\mathrm{D}[\mathrm{P}]$ in relationship (2) reflects the fact that a decision is required. Once the process $[\mathrm{P}]$ is explicitly selected, traditionally by the process planner after the design solution has been generated, then process related constraints which can be influential to the life-cycle consequences are introduced. These can be expressed as:

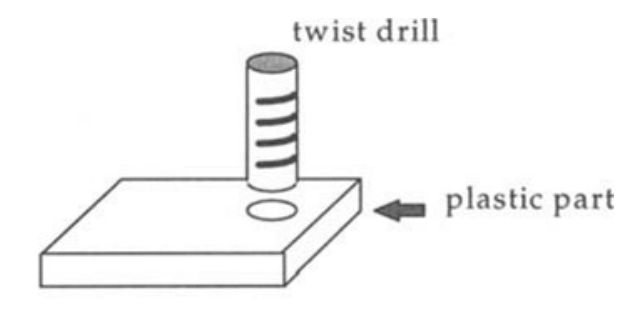

\section{$[\mathrm{M}]=$ thermoplastic; $[\mathrm{P}]=$ drilling:}

- secondary operation introduced;

- more time, lower production rate

- no 'weld lines' formed etc...

Figure 4 Influence of process $[\mathrm{P}]$ factor.

$$
[d]_{E}\{[P]\}---\cdot--->\left\{[C]_{P}\right\}
$$

An explicit decision commitment $[d]_{E}\{[P]\}$ resulting in the selection of a process results in the introduction of a set of process related constraints $\left\{[C]_{P}\right\}$ influencing the definition of feature parameters $[F]_{P}$.

For instance, selecting a drilling operation (figure 4) and hence specific drilling machine introduces limits on the range of diameters that can be drilled, the tolerances possible etc. On the other hand, selecting a different process, such as a laser-drilling, results in a different range of diameters that can be drilled. 


\section{Parameter Value [V] Factor}

Each feature parameter $[\mathrm{F}]_{\mathrm{P}}$ has an associated set of possible values $\{[\mathrm{V}]\}$; for instance, the parameter depth for the feature hole has a set of possible values ranging from $\{0$ to thickness of part $\}$ and the parameter orientation angle has a range from $\left\{0\right.$ to $\left.360^{\circ}\right\}$. Therefore, a feature parameter decision space $\mathrm{S}$ e.g.(angle, depth, radius etc.), requires the consideration of a feature parameter (e.g. angle), giving rise to a decision point because a specific value has to be specified for that parameter. Hence from (1) this relationship can be expressed as:

$$
S\left\{[F]_{P}\right\} \text {----requires----> }[d]_{E}[F]_{P} \text {-----gives rise to -------> } D\{V\}
$$

The commitment of a value to a parameter from the possible range, together with the selection of a process (relationship 3) can give rise to life-cycle consequences [LCC], these reflected in the behaviour of performance measures such as cost and time.

$$
[d]_{E}\{[V]\}+[d]_{E}\{[P]\}----\cdot---->[L C C]
$$

read as:

The committed decisions $[d]_{E}\{[V]\}$ concerning a value assigned to a feature parameter together with the decision committed concerning the selection of a process i.e. $[d]_{E}\{[P]\}$, can give rise to a number of consequences on performance measures in life-cycle phases.

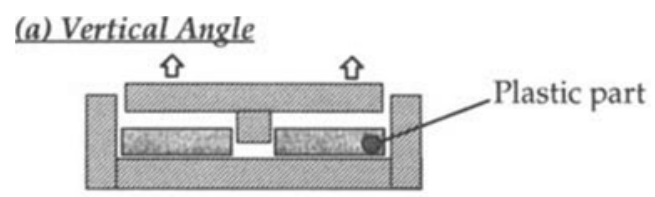

\section{(b) Oblique Angle}

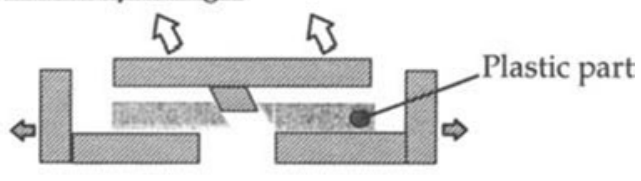

- complex mould design \& construction

- higher mould cost

- longer mould design process

- longer part-ejection etc...

Figure 5 Influence of parameter values [V]. 
The example schematically illustrated in Figure (5) shows how the value of the parameter orientation angle $\theta$ of a hole feature, using an injection moulded process [P] effects the performance measures, in terms of mould construction time and cost. Cost is influenced because the mould ejection system is more complex when compared to a part having a vertical hole. This complexity affects the mould design and construction time during the mould design stage. It also influences the time taken to eject parts during the injection moulding process.

\subsection{Knowledge Model}

From the relationships established, the knowledge model required for supporting life-cycle providence is one organized as schematically illustrated in figure(6). From relationship (2), depending on the feature $[\mathrm{F}]$ being added to a part and the material $[\mathrm{M}]$ chosen, then a set of possible processes $\{[\mathrm{P}]\}$ is identified. This means that knowledge for supportin 3 this relationship needs to be captured and organized on $\{[\mathrm{F}]$ and $[\mathrm{M}]\}$ combinations in order to enable designers to become knowledgeable of possible life-cycle processes [P]s that can be employed when $\{[\mathrm{F}]$ and $[\mathrm{M}]\}$ are being specified.

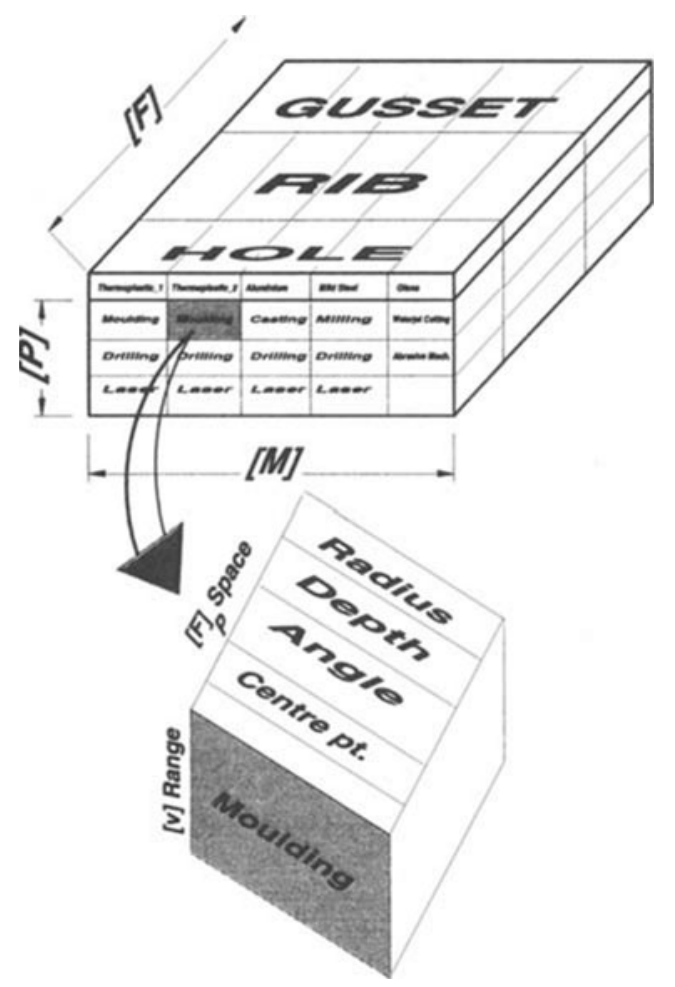

Figure 6 Knowledge Organization based on [F], [M] and [P]. 
Then, the designer can have an insight into possible life-cycle consequences by exploring the effect of selecting a specific process $[\mathrm{P}]$ from the identified set. For instance, as schematically illustrated by shading in Figure (6), the selection of injection moulding as the process for generating the hole in the thermoplastic_2 part gives rise to a rationalised set of knowledge concerning that problem specific [F],[M] \& [P] combination. Based on relationship [4], this set of knowledge, will provide designers with a decision space $\mathrm{S}$ (what diameter, what depth etc.) for that feature $[\mathrm{F}]$ and a range for each parameter value, constrained by $[\mathrm{C}]$. Hence knowledge has to be also modelled on an $\{[\mathrm{F}],[\mathrm{M}],[\mathrm{P}]\}$ combination basis so as to rationalize the knowledge required for providing problem-specific providence. Based on relationship (5), depending on the parameter value $[\mathrm{V}]$ specified to a feature parameter $[\mathrm{F}]_{\mathrm{P}}$, the designer can then explore the resulting behaviour of the performance measures in the different life-cycle phases.

Each value assigned to the feature parameters will lie within a range, for which there is a substantial difference in the behaviour of performance measures of the different life-cycle phases. This is schematically illustrated in Figure (7), for ranges of the feature parameter orientation angle. This means that knowledge on the behaviour of performance measures has to be captured and organized on the basis of different parameter value [V] ranges for different feature parameters $[\mathrm{F}]_{\mathrm{p}}$.

\section{Example}

Assume that a circular hole feature is being added to a part, made of Thermoplastic_2 material. From knowledge organized as in Figure(6), the designer becomes aware of a number of processes that can be used in this case and opts to explore the consequences of choosing an injection moulding process $[\mathrm{P}]$, rather than using a drilling or laser process. This combination defines the decision space for the hole feature parameters and the range for each parameter, as schematically illustrated in Figure (6). Let us assume that the designer is exploring the definition of a value to the feature parameter orientation angle. A value of angle $=O^{\prime \prime}$ lies within a range which will for instance result in a set of performance measures for the different life-cycle phases as illustrated in Table(2). This is derived from knowledge organized as schematically illustrated in Figure (7).

Table 2 - Angle $=\mathrm{O}^{\circ}$

\begin{tabular}{llll}
\hline & Cost & Time & Quality \\
\hline Manufacturing & 10 & 5 & 5 \\
Assembly & 8 & 5 & 5 \\
Use & - & - & 10 \\
Service & 7 & 12 & 20 \\
Disposal & 7 & 12 & - \\
Total & 32 & 34 & 40 \\
\hline
\end{tabular}

Table Notation:

higher cost $=$ worse effect longer time $=$ worse effect ; higher quality $=$ better effect 
The designer may want to explore the alternative consequences on the different life-cycle phases by specifying an orientation angle of $45^{\circ}$. From the example provided earlier in Figure(5), the performance measure of the different life-cycle phases are affected by such a decision, for a number of reasons as stated in Table 3 . Tables 2 and 3 give a relative indication of the different behaviour of the performance measures for different life-cycle phases. For instance, an oblique hole results in a higher manufacturing cost (20) when compared to the cost of a vertical hole (10). However, the quality of the part as perceived by the client during the 'Use' phase has a higher score (40). Besides giving an insight into the behaviour of individual life-cycle phases, the overall total of the performance measures will give a relative indication of the complete life-cycle effect. For instance, the total life-cycle cost for an oblique hole (64) is relatively larger than that of a vertical hole (32) but the overall lifecycle quality is better (65). It is such an insight into the behaviour of life-cycle phases that enables designers to explore their design synthesis decisions.

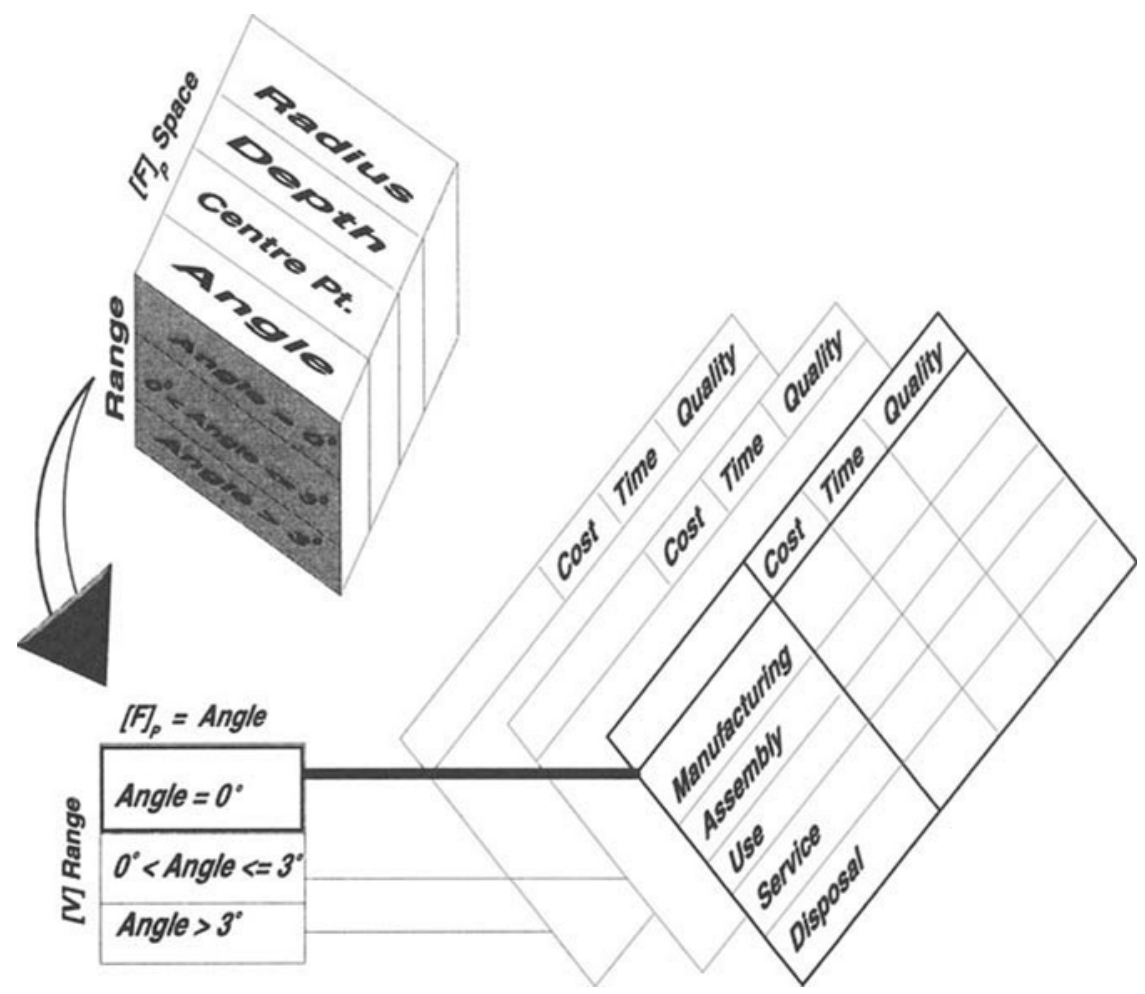

Figure 7 Behaviour of Performance Measures as influenced by values [V]. 
Table 3 Angle $=45^{\circ}$

\begin{tabular}{llll}
\hline & Cost & Time & Quality \\
\hline Manufacturing & 20 (complex mould) & $\begin{array}{l}40 \text { (longer mould design \& } \\
\text { construction + part ejection) }\end{array}$ & 5 \\
Assembly & $\begin{array}{l}20 \text { (design, construction of } \\
\text { special jigs) }\end{array}$ & $\begin{array}{l}30 \text { (orientation of fastener } \\
\text { takes longer) }\end{array}$ & 5 \\
Use & - & - & $\begin{array}{l}40 \quad \text { (happier } \\
\text { client) } \\
\text { Service }\end{array}$ \\
Disposal & 14 & 20 & 15 \\
Total & $\begin{array}{l}\text { (complicated disassembly) } \\
\text { more overheads) }\end{array}$ & $\begin{array}{l}\text { (takes longer) } \\
\text { (longer disassembly) }\end{array}$ & - \\
& 64 & 105 & 65 \\
\hline
\end{tabular}

\section{ENVISAGED USE OF MODEL FOR DESIGN EXPLORATION}

As explained, life-cycle consequences generated, depend on the combination of the commitment of a number of decisions concerning the identified Feature [F], Parameter Values [V], Material [M] and Process [P] factors together with the constraints [C] introduced with these commitments. These factors correlate with similar characteristics identified by (Tjalve 1979; Nakazawa 1984; Hubka et al. 1988; Jacobsen 1989) which are however not formally related in a way to enable their combination to be employed for design providence during decision making. As established, the relationships provide a framework for design synthesis decision making which can be supported by the proposed knowledge model. They highlight that for life-cycle providence, the design phase is to be considered the phase where to commit life-cycle decisions. Such a life-cycle design exploration approach leads to a fundamentally different method from for instance one using traditional DFX tools as it supports the exploration of consequences whilst the synthesis decisions are being committed. Also, the organization of knowledge based on the identified structured relationships provides a wider view than DFX - a design for multi-X (DFLX) view. It is envisaged that designers and design teams can therefore interact with the proposed knowledge structure as a means of how to coordinate their synthesis decision making process in a way which promotes provident reasoning. If this is established, the knowledge model is a basis on which to capture and organize knowledge for use in a Knowledge Intensive $C A D$ system for concurrent design as:

- it enables providence to take place during the commitment of design decisions, rather than later as with analysis type tools such as FMEA and DFX;

- it promotes life-cycle design exploration;

- it identifies the type of knowledge that needs to be captured and how it should be organized within a KICAD e.g. combination of $[\mathrm{F}] \&[\mathrm{M}]$ or $[\mathrm{F}],[\mathrm{M}] \&[\mathrm{P}]$ etc.;

- it results in the provision of problem specific providence unlike for example with DFX tools because it takes into consideration specific combinations [M],[F],[V] etc.;

- unlike DFX, it supports multiple life-cycle perspectives, as illustrated in Tables 2 or 3;

- allows a life-cycle strategy to be considered and committed during design. 


\section{FUTURE DIRECTIONS AND CONCLUSION}

As demonstrated, the proposed knowledge structure supports life-cycle providence during the design of components. Work is still taking place to control the scaling up of knowledge for realistic design problems through the classification of factors such as processes [P] into primary, secondary, finishing etc. Form features $[\mathrm{F}]$ currently relate to the manufacturing phase, this requiring research to potentially relate them to other life-cycle phases such as assembly, disposal etc. Also, the knowledge structure needs to be extended further to support feature-feature interactions and to handle situations where knowledge is unavailable. Nonetheless, case-studies presented suggest that if the knowledge is validated, then the amalgamation of a feature-based CAD system together with a computer model of knowledge of consequences would be a type of KICAD system which allows life-cycle exploration based on providence to be performed during design synthesis.

\section{REFERENCES}

Andreasen, M. M. and Olesen, J. (1990). The Concept of Dispositions. Journal of Engineering Design 1(1), 17-36.

Askin, R. G. and Sodhi, M. (1994) Organization of Teams in Concurrent Engineering, in Handbook of Design, Manufacturing and Automation (ed. R. Dorf and A. Kusiak), John Wiley \& Sons Inc.,. New York.

Borg, J. and MacCallum, K. J. (1995). A HyperCAD Expert System For Plastic Product Design. 3rd International Conference, Computer Integrated Manufacturing, Singapore, World Scientific.

Bowen, J. (1995). Using Dependency Records to generate Design Coordination advice in a Constraint-Based Approach to Concurrent Engineering. Co-operation In Manufacturing:CIM AT WORK, Kaatsheuvel, The Netherlands, CIMMOD/CIMDEV.

Cleetus, K. J. (1993) Virtual Team Framework and Support Technology, in Concurrent Engineering Tools and Technologies for Mechanical System Design (ed. E. J. Haug), Springer-Verlag,. USA.

Corbet, T., J., Dooner, M., Meleka, J. and Pym, C. (1991). Design For Manufacture Strategies, Principles and Techniques, Addison-Wesley Publishers Ltd.,. England.

Finger, S. and Dixon, J. R. (1989). A Review of Research in Mechanical Engineering Design. Part II Representations, Analysis and Design for the Life Cycle. Research in Engineering Design 1, 121-137.

Gardner, S. and Sheldon (1993). Consensus Statement no.10.8. WDK Workshop on Design For X, Lyngby, Denmark, Technical University of Denmark.

Healey, J. (1994). Failure Mode and Effects Analysis in Engineering Designer. Journal of The Institution of Engineering Designers(Jan/Feb.), 4-7.

Hubka, V. and Eder, E. (1988). Theory of technical systems: A total concept theory for engineering design, Springer-Verlag,. Berlin/Heidelberg.

Jacobsen, K. (1989). The interrelation between product shape, material and production method. International Conference on Engineering Design ICED'89, Harrogate, Mechanical Engineers Publications Ltd. 
MacCallum, K. J. (1991). Expert System Architecture Requirements For Concurrent Design. The World Congress on Expert Systems, Florida, USA.

Molloy, E. and Browne, J. (1993) A knowledge-based approach to design for manufature using features, in Concurrent Engineering - Contemporary issues and modern design tools (ed. H. R. Parsaei and W. G. Sullivan), Chapman \& Hall,. London.

Nakazawa, H. (1984). Information Integration Method. Design and Synthesis, Japan, Elsevier Science Publishers B.V. (North-Holland).

Norell, M. (1993). The Use of DFA, FMEA AND QFD as tools for Concurrent Engineering in Product Development Processes. International Conference on Engineering Design ICED'93, The Hague.

Olesen, J. (1992). Concurrent Development in Manufacturing - based on dispositional mechanisms/, PhD The Technical University of Denmark,. Lyngby.

Tjalve, E. (1979). A Short Course in Industrial Design, Newnes-Butterworths,. London.

Tomiyama, T., Umeda, Y., Ishii, M., Yoshioka, M., et al. (1995). Knowledge systematization for a knowledge intensive engineering framework. First IFIP Workshop on Knowledge Intensive CAD, Helsinki University of Technology, Espoo, Finland.

Wierda, L. S. (1991). Linking Design, Process Planning and Cost Information by Featurebased Modelling. Journal of Engineering Design 2(1), 3-19.

\section{BIOGRAPHY}

Jonathan Borg graduated in Mechanical Engineering from the University of Malta in 1989, after which he worked for 3 years with a Water Authority responsible for CAD systems employed for designing desalination plants. During this period, he also formed part of a team responsible in designing and implementing a computer based mathematical model of a water aquifer. In 1992 he joined the University of Malta, responsible for lecturing and carrying out research in CAD/CAM. In 1993, he graduated with an MSc in Computer Aided Engineering Design from the University of Strathclyde, Glasgow, with whom he is currently a $\mathrm{PhD}$ candidate. He is a member of the Institute of Engineering Designers (UK), the Institute of Mechanical Engineers (UK) and the Society of Manufacturing Engineers (USA).

Professor Ken MacCallum graduated in Naval Architecture from the University of Glasgow, and later with a $\mathrm{PhD}$ for research into the application of computer graphics to free-form surface design from the Imperial College, University of London. After three years with a software company, he joined the University of Strathclyde, establishing the CAD Centre in 1985 as a research and postgraduate centre. Ken MacCallum's main research area has been the application of Artificial Intelligence to Engineering Design. He has led projects concerned with intelligent design modelling, data exchange, computer based design coordination, and computer aided learning. He is editor of the International Journal on Artificial Intelligence in Engineering, a member of IFIP WG5.2, and has been on the Technical Programme Committees of a large number of Conferences and Workshops concerned with computer aided design. He is currently the Head of Design, Manufacture and Engineering Management Department in the Faculty of Engineering, University of Strathclyde. 